\title{
Restricciones a porte de velo islámico. Reflexiones sobre la discusión comparada y la incipiente jurisprudencia chilena (Corte de Apelaciones de Santiago)
}

\author{
Comentario de Yanira Zúñiga Añazco
}

Santiago, treinta y uno de mayo de dos mil once.

\section{VISTOS:}

A fs. 1 comparece doña Fabiola Palominos Flores, RUT 11.629.450-8, domiciliada en Rosas 1190 depto. 307, ciudad de Santiago, quien interpone este recurso de protección I.C. 4670-2010, a favor de ella misma, en contra de la Sucursal Rondizzoni del Banco del Estado, ubicado en Santiago, en Avenida Viel Poniente 1965, local 2, porque cuando concurrió hasta la Caja a cobrar un cheque, el cajero respectivo la obligó a quitarse el velo islámico que llevaba, frente al Jefe de atención al cliente, lo que considera un trato vejatorio, humillante y discriminatorio en su libertad religiosa. Agrega que su cara estaba descubierta y que su hiyab sólo oculta el pelo y el cuello. Después de aquello, su cheque fue pagado.

La recurrente no señala disposición expresa de orden constitucional que estime contrariada por lo sucedido, ni solicita a esta Corte adoptar alguna medida a este respecto. Sólo deja constancia del hecho.

La recurrente acompaña una copia del oficio agregado a fojas 7 de autos, respuesta del Banco a la Superintendencia de Bancos e Instituciones Financieras, en el que se señala que es efectivo que el cajero pidió a la recurrente que se quitara parte del atuendo que cubre su rostro, para verificar su identidad, cumpliendo con ello el funcionario con el procedimiento normado para el cobro de documentos, que es igual para todos los clientes, por lo que no ha habido una actitud discriminatoria.

Se dispuso pedir informe al recurrido, respondiendo mediante oficio que obra a fojas 14, el Gerente General Ejecutivo del Banco del Estado, don Pablo Bernardino Piñera Echeñique, quien señaló que el cajero solicitó a la recurrente que se quitara parcialmente el atuendo que le cubría los contornos de su rostro, a lo que la cliente se negó, pero más tarde, ante las explicaciones del Jefe de Atención a Clientes, respecto del por qué es necesario ver el rostro de las personas, ella entendió y aceptó.

Agrega que el Banco es sumamente cuidadoso al momento de verificar la identidad de quien hace una transacción bancaria, para evitar la suplantación de clientes, ya que han tenido varios intentos de hacerlo mediante el uso de distintos atuendos, como gorros, lentes oscuros, bufandas, etc. 
A fs. 26, la recurrida acompaña video en que se aprecia el instante de cobro del cheque, en el que se puede advertir que el atuendo islámico que usa en la ocasión cubre su cabello y cuello y el contorno de su rostro.

En los alegatos de los apoderados de recurrente y recurrida, entre otras cosas, el primero admitió que en ocasiones anteriores, en el mismo Banco, otras Sucursales, el problema no se había presentado y que el carnet de identidad que portaba en la ocasión la amparada, tenía una foto en que aparecía sin la prenda islámica y con su pelo suelto, lo que aparece del mismo recurso en el cual se indica que luego de los hechos, obtuvo una nueva cédula de identidad, con la prenda en cuestión. El segundo, señaló que el Banco estaba dando instrucciones para que este tipo de situaciones se ponderara en mejor forma por el personal, sin olvidar los parámetros de seguridad mínimos que se requieren.

\section{Y TENIENDO PRESENTE:}

$1^{\circ}$.- Que, la Acción Constitucional de Protección pone en movimiento a la Jurisdicción, a fin de que conozca de una acción u omisión ilegal o arbitraria que importa una amenaza o perturbación actual a alguno de los Derechos Constitucionales, por lo que para que sea pertinente, debe, a lo menos, cumplir con las siguientes condiciones:

Debe tratarse de una amenaza o perturbación que se procure que cese, mediante la orden correctiva que emane del Tribunal, para restablecer el imperio del derecho y asegurar la debida protección del afectado y por otra parte, debe afectar uno o más derechos de los que se mencionan en el artículo 20 de la Constitución Política de la República.

$2^{\circ}$.- Que, al interponerse el recurso y durante toda su tramitación, no se mencionó con precisión cuál sería específicamente el derecho constitucional vulnerado y, además, no se hizo petición alguna al tribunal, precisa, de la forma en que se pretendía que se la amparara de la violación de un derecho que ya se habría conculcado, mediante una acción totalmente agotada, en una Sucursal del Banco recurrido.

$3^{\circ}$.- Que, aunque esta Corte estimara, que del cuerpo del escrito, pudiera desprenderse algún derecho que abarque lo que se describe, y se llegara a una estimación de la garantía que podría haber sido la agredida con ese hecho, todo lo cual no se ha expresado con precisión por la recurrente que obra personalmente al inicio del procedimiento, es lo cierto que no existe posibilidad alguna de restablecer el imperio del derecho, esto es restituirlo, devolverlo, reintegrarlo, reponerlo o restaurarlo, desde que del propio recurso aparece que se trata de una acción que se supone injusta, que se encuentra agotada, no se mantiene en el tiempo, ni se ha repetido, y que sólo se produjo en una Sucursal del Banco recurrido y no en otras del mismo Banco, por lo que lo sucedido, parece a estos juzgadores más la actuación más allá de lo debido y falta de ponderación y cuidado, de funcionarios particulares que habrían carecido del criterio que se requiere, para el cumplimiento armónico de sus labores, en relación con los intereses de los clientes. 
$4^{\circ}$.- Que, por lo mismo que se ha dejado dicho, y apareciendo de los antecedentes que los hechos que se denuncian, aparecen más como el acto puntual y falto de cuidado de funcionarios específicos, obrando más allá de lo estatuido por la recurrida, con un sentido del deber exacerbado, lo que no le había ocurrido a la afectada en otras sucursales del mismo Banco, no aparece evidente, a mas de que no se ha pedido nada a este respecto, establecer la forma en que podría darse protección a la afligida, ante eventuales actos futuros similares que la perturben.

Y visto, además, lo dispuesto en el artículo 20 de la Constitución Política de la República y Auto Acordado de la Excma. Corte Suprema sobre Tramitación y Fallo del Recurso de Protección, se rechaza el deducido en estos autos por Fabiola Palominos Flores, en su propio favor.

Acordado con el voto en contra del ministro señor Cerda, quien estuvo por otorgar el amparo que se solicita, por la razones y en los términos que pasa a precisarse:

1) A juicio de este juez es necesario desentrañar el significado de la voz "hiyab" por cuanto no es una palabra que corresponda al léxico usualmente empleado en nuestro medio.

Etimológicamente quiere decir "cortina", "barrera"; forma de separación entre lo puro y lo impuro, lo selecto y lo no selecto, lo culturalmente identificado con lo extraño. Surge de la paulatina digresión social entre leales y desleales a Mahoma, entre las mujeres que lo siguen y las que no. Esta idea no sólo se extiende al ámbito de las féminas, sino que también alcanza a los hombres, toda vez que se nutre de la concepción de que había que proteger la intimidad de Mahoma frente a terceros.

Tanto el Corán como el Hadiz conciben al hombre y a la mujer como seres modestos, decentes y corporalmente pudorosos, aspectos que tradicionalmente se han incorporado a la identidad del islamismo, pasando a formar parte esencial de una cultura, más que de una religión.

Tal vez la transcripción de las Azoras 24 y 33 del Corán ayuden a ilustrar lo que en este primer prisma hermenéutico este juzgador pretende demostrar.

Azora 24: "Di a las mujeres que bajen la vista con recato, que sean castas y no muestren más adornos que los que están a la vista, que cubran su escote con el chal...".

Azora 33: "iProfeta! Di a tus esposas, a tus hijas y a las mujeres de los creyentes que se cubran con el manto. Es mejor para que se las distinga...”.

De estos pasajes los seguidores del Corán extraen la idea esencial de distinguirse de los demás en cuanto a una actitud de modestia, de decencia y de pudor corporal, distinción que conlleva reconocimiento y status. Por algo las esclavas sólo podían portar el "yilbab", empero no el "hiyab", reservado a las mujeres libres.

2) Desde el punto de vista, ahora, sociológico, no parece merecer dudas que en los tiempos presentes el tema de la hiyab está íntimamente asociado a la emancipación de un pueblo que ha venido históricamente soportando conflagraciones que lo han inclinado a aferrarse a determinados símbolos de unidad e identidad.

Políticas de inmigración, sumadas a una globalización de la humanidad, han implicado la inserción de los islamistas en sociedades normalmente ajenas a su idiosincrasia. De esta realidad no ha quedado ajena la mujer, que utiliza la hiyab como una forma de mostrar, a la vez, fidelidad a sus orígenes e integración a una comunidad que, desde su punto de vista, exhibe indiscutibles abolengos. 
Siempre desde una visión sociológica del problema, la mujer islamita incorporada al tráfago de sociedades occidentales ajenas a su mundo cultural, justamente acude al hiyab para demostrar independencia; para significar capacidad en el trabajo; para exhibir sus virtudes en el estudio. En suma, para coparticipar en un medio en cierto modo hostil en punto a los parámetros de la intimidad y privacidad, preservando en él la pureza de su concepción de la vida, integradora, como se ha dicho, de modestia, decencia y pudor corporal.

Lo fundamental para este discrepante es, entonces, que no se está en presencia de un símbolo religioso que de alguna manera -como se lo ha considerado hogaño en países como Francia y Turquía- amenace perturbar la libertad de credos en Estados definidamente laicos.

Se trata, en cambio, del principio de identidad cultural.

La mujer que en una realidad como la chilena se desplaza públicamente con hiyab, explicita con orgullo su pertenencia a lo que juzga más propio, a saber, la civilización islámica.

4) Si lo anterior no es erróneo, se tiene que lo que está de por medio en el presente recurso es el derecho a la propia imagen, bajo la forma de opción por símbolos culturales determinados.

El derecho a la igualdad ciertamente es comprensivo de esos aspectos que forman parte del patrimonio personal y que no pueden extraerse del ámbito de aplicación del artículo 1 de la Constitución Política de la República, centrado en el progreso de cada quien, conforme a su propia personalidad.

5) Claro está que el ejercicio del derecho a la igualdad puede verse limitado a través de lo que se denomina discriminación positiva.

Es un hecho, también, que las libertades pueden sufrir limitaciones, que en todo caso han de sujetarse a la restrictividad propia de lo excepcional.

Se ha dicho que el BancoEstado aquí concernido estuvo en la obligación de proceder como lo hizo, para dar cumplimiento a instrucciones de la Superintendencia de Bancos y a reglamentaciones internas destinadas a asegurar que el cheque se pagara a quien correspondía.

No debe desconocerse que esa clase de seguridades puede llegar a justificar limitaciones a la igualdad y a la libertad, empero, la comunidad jurídica internacional ha venido exigiendo a tales límites que cumplan tres condiciones para legitimarse, entre las cuales, que sean necesarias para lograr la finalidad que se aduce como justificativa de su adopción.

6) Se ha sostenido por el recurrido que el cajero y su jefe tenían la obligación de exigir a la dama que retirara su hiyab, como única manera de comprobar su identidad.

A diferencia de otros distintivos como el "burqa", el "niqab" o el "chador", la hiyab no cubre el rostro. Es un pañuelo que abraza el cabello y, a veces, el cuello.

Al igual que la toca de una religiosa católica, mantiene al descubierto el óvalo de la cara y en caso alguno impide la comunicación.

Cualquier interlocutor de una dama que porte hiyab distinguirá perfectamente con quién está dialogando. 
7) Siendo así, concluye este juez que no ha existido y no existe razón para haber obligado a la recurrente a retirar el hiyab como única manera de asegurar su identificación.

De hecho, múltiples son las diferencias faciales que experimenta una persona con el transcurso del tiempo, sea por ministerio de la naturaleza, sea por deliberada intervención.

Quien obtiene una licencia estando rasado, no habrá de tener normalmente inconvenientes en cobrar un cheque luciendo barba o bigotes; la dama que se produce con sombreros de diversa suerte, se mostrará distinta según sus clases; el arreglo facial femenino no tan extrañamente generará apariencias diversas; y así...

Máximas de experiencias todas éstas que no pueden quedar al margen de esta decisión.

8) Aún de entenderse que es necesario buscar mecanismos de aseguramiento para pagar los cheques a quienes legalmente corresponda, ellos en caso alguno podrán hacer abstracción o tabla rasa de aspectos inherentes a la personalidad de cada quien, los que forman parte del juego democrático de igualdades y libertades.

Ergo, el discrepante considera ilegítimo el comportamiento que se reprocha al BancoEstado, directamente atentatorio a la integridad psíquica, la no discriminación y la libertad personal de Fabiola Palominos Flores, bienes jurídicos amparadas por los numerales $1^{\circ}, 2^{\circ}$ y $7^{\circ}$ e) del artículo 19 de la Constitución Política de la República, lo que lo mueve a conferir la protección, disponiendo que la Superintendencia de Bancos e Instituciones Financieras instruya en el sentido que cualquier medida destinada a salvaguardar los cometidos propios de sus normados ha de ser del todo respetuosa de tales garantías, y disponer que el BancoEstado adecue sus procedimientos internos a la misma exigencia.

Regístrese. Comuníquese y archívese en su oportunidad.

Redacción del fiscal judicial Juan Manuel Escandón Jara y del voto, su autor.

$\mathrm{N}^{\circ}: 4670-2010$.

Pronunciada por la Sexta Sala de esta Iltma. Corte de Apelaciones de Santiago, conformada por el ministro señor Carlos Cerda Fernández, con el fiscal judicial don Juan Manuel Escandón Jara y el abogado integrante señor Enrique Pérez Levetzow.

\section{COMENTARIO}

El recurso de protección planteado por Fabiola Palominos Flores introduce en nuestro ordenamiento jurídico la discusión en torno al velo islámico, que ha ocupado parte del debate político-jurídico de los estados europeos en los últimos años y ha dado origen tanto a medidas de prohibición general de utilización de símbolos religiosos en las escuelas públicas como, a la recientemente aprobada en Francia, interdicción legal de porte de velo integral en los espacios públicos.

Estas medidas han nutrido una rica discusión (doctrinal y jurisprudencial) sobre la protección de la libertad religiosa en nuestros estados contemporáneos, enfrentando a posturas multiculturalistas -alineadas, en general, con el respeto de la diversidad cultural y, por tanto, muy críticas con estas medidas- con posturas nacionalistas (algunas con 
ciertos elementos de republicanismo) que reivindican la recuperación de ideales como la cohesión nacional, a través de una gestión de la migración que privilegie las políticas de asimilación cultural, de las cuales estas medidas formarían parte. Este debate ha permitido, además, reflexionar sobre el lugar de la laicidad como principio conformador del plexo democrático. Por otro lado, la cuestión del velo islámico ha generado también un quiebre entre las pensadoras feministas que, unas veces han apoyado estas disposiciones, como forma de combatir la sujeción cultural femenina que las mismas vehiculan, y otras han defendido la libertad de las mujeres para construir estrategias político-culturales propias (o intraculturalmente pactadas) destinadas a poner fin a estos fenómenos de sumisión. En síntesis, la cuestión del velo islámico no sólo ha sido debatida en clave de igualdad cultural sino también en clave de igualdad de género.

El fallo de primera instancia de la Corte de Apelaciones de Santiago recaído en el recurso de protección antes aludido y que será objeto medular de este comentario no alcanza, ni siquiera, a rozar estos debates, a diferencia del voto de minoría que, en cambio, insinúa algunos de ellos. Al contrario, la cuestión es reducida en dicha sentencia a un mero problema de condiciones de procedencia del recurso de protección. Como se observará de su lectura, la tesis central del fallo en análisis es que, en la medida que el acto impugnado (la exigencia del cajero del banco de que la recurrente retire el velo que portaba para comprobar su identidad, como condición para el pago de un cheque) sería un acto único y se habría agotado en el tiempo, no existiría "posibilidad alguna de restablecer el imperio del derecho, esto es, restituirlo, devolverlo, reintegrarlo, reponerlo o restaurarlo" (considerando $3^{\circ}$ ). Parece ser que, por lo mismo, el tribunal considera irrelevante pronunciarse claramente sobre el o los derechos eventualmente afectados ${ }^{1}$.

En el considerando $4^{\circ}$ de la sentencia, el tribunal no sólo afirma que se trata de un hecho aislado sino que descarta, además, la arbitrariedad ("los hechos que se denuncian, aparecen más como el acto puntual y falto de cuidado de funcionarios específicos, obrando más allá de lo estatuido por la recurrida, con un sentido del deber exacerbado”).

Ambas conclusiones son problemáticas porque no reparan en que la falta de una normativa interna más clara del banco, que permita balancear adecuadamente las exigencias de seguridad con el respeto de la libertad de culto, es precisamente lo que posibilita que la decisión sobre las condiciones que deben satisfacer los clientes para acreditar su identidad, quede entregada -sin criterios rectores- a los cajeros.

Mirado así, es posible sostener -y es lo que voy a argumentar aquí- que la arbitrariedad tiene su origen en este caso en una omisión que desencadena una acción arbitraria.

\footnotetext{
${ }^{1}$ Parece curioso, sin embargo, que el tribunal utilice como premisa de su razonamiento a este respecto la circunstancia de que la recurrente -quien interpuso inicialmente el recurso sin patrocinio de abogadono mencionara determinadamente la disposición constitucional violada, no sólo porque con esta lógica establece una carga de calificación jurídica a quien no está en posición de hacerlo, sino porque la misma parte expositiva de la sentencia establece que la recurrente estima que la conducta impugnada es "un trato vejatorio, humillante y discriminatorio en su libertad religiosa" (párrafo primero), lo que supone -desde luego- que la recurrente sí realizó una calificación jurídica preliminar de derechos conculcados. En efecto, resulta difícil imaginar que dicha afirmación no involucre la afirmación implícita de conculcación de la libertad religiosa en relación con la igualdad.
} 
Dado que propongo analizar esta cuestión desde esta perspectiva, cabe preguntarse, en primer lugar, por qué la recurrida estaría obligada a contar con tal normativa ${ }^{2}$. La razón está en lo que pierde de vista el fallo: la libertad de culto es un derecho que protege, entre otras manifestaciones, la exteriorización de la convicción religiosa a través de símbolos visibles y que, por ende, involucra exigencias especiales de protección, cuando se trata de convicciones religiosas minoritarias, a efectos de garantizar el ejercicio de todas las convicciones en un plano razonable de igualdad.

Lo anterior no es más que el resultado de la aplicación del criterio democrático en lo concerniente a la evaluación de las restricciones, el cual establece que sólo son legítimas aquellas restricciones necesarias en una sociedad democrática. Pese a que la conclusión respecto del porte de esta prenda fue la opuesta, la Corte Europea ha aplicado este criterio en el asunto Leyla Sabin vs Turquía, al considerar legítima la restricción de porte de velo en universidades turcas, dado que aquélla protege precisamente a las mujeres no musulmanas, quienes constituyen una minoría en dicho país.

Creo, entonces, que hay razones contundentes para aplicar aquí la misma aproximación. En efecto, si el estándar de protección no considera las condiciones de ejercicio de estos derechos, que son -como se encarga de precisar el voto disidente de primera instancia- de carácter sociológico, se corre el riesgo de trivializar la libertad de culto y, desde luego, de no ampararla. De hecho, la alegación de la parte recurrida en orden a que el excesivo celo del cajero se fundaría en el intento de evitar suplantaciones de personas debido a que "han tenido varios intentos de hacerlo mediante el uso de distintos atuendos como gorros, lentes oscuros, bufandas, etc.”, refleja que el porte de un símbolo ligado a prácticas religiosas minoritarias, en un determinado contexto cultural (como ocurre con el velo islámico en Chile), puede ser fácilmente asimilado al porte de un artículo de moda, estético o de abrigo.

En este sentido, el razonamiento del voto de minoría de la sentencia de primera instancia es un aporte, al hacerse cargo -aunque de una manera algo farragosa en el raciocinio y en la identificación de los derechos afectados- de esta dimensión del problema. De otro lado, el voto de minoría del fallo de segunda instancia implícitamente parece compartir esta aproximación, al señalar que "si bien es aceptado que esta acción debe adoptar medidas cuando se la acoge y que, por otra parte, cuando el acto que la motivó se encuentra concluido no es posible hacerlo [...], no es posible omitir la protección requerida por tal circunstancia de hecho, porque es claro que no ha acudido a esta sede reclamando únicamente respecto de la entidad bancaria en la que se produjo el incidente, sino obviamente porque precisa de una medida de cautela de carácter general de la que han de ser sujetos pasivos todos quienes habitan en la República”.

${ }^{2}$ Dejaré de lado lo referente a la polémica sobre el efecto horizontal de los derechos que, como se sabe, discute la posibilidad de obligaciones positivas de satisfacción de derechos respecto de los particulares. 